\title{
Teaching Resources Construction and Teaching Methods Research of Data Structure
}

\author{
Yuping Qin ${ }^{1, a^{*}}$ and Qiangkui Leng ${ }^{2, b}$ \\ ${ }^{1}$ College of Engineering, Bohai University, Jinzhou 121013, China \\ ${ }^{2}$ College of Information Science and Technology, Bohai University, Jinzhou 121013, China \\ aqlq888888@sina.com, bqkleng@126.com \\ *The corresponding author
}

\begin{abstract}
Keywords: Data structure; Teaching resource; Teaching method; Application ability
\end{abstract}
\begin{abstract}
According to the characteristics of data structure and the requirements of practical personnel, the necessity and guiding ideology of the teaching resources construction and the teaching methods research of data structure are illustrated firstly, and then the contents of teaching resources construction and the teaching methods of students autonomous learning guided by teachers are expounded in detailed. Finally, the results of teaching practice in recent five years are given.
\end{abstract}

\section{Introduction}

Data structure is the core course of computer specialty. It plays a very important role in the training of computer professionals [1,2] In recent years, many colleges and universities have carried out teaching resources construction and teaching method reform of Data structure, and some achievements have been obtained[3-12]. However, there are still many problems in applied undergraduate colleges. The traditional model, which teachers introduce theory in classroom and students test algorithms in experimental class, has been not fundamentally changed. The interaction between teachers and students is not enough. The resources for students autonomous learning is lack. The combination of theory and practice is not close. The methods of cultivating students comprehensive quality and practical ability are not exact. The contents of teaching resources are lack of practicality and pertinence. The management of teaching resources is lack of effectiveness and timeliness. The design of teaching platform is lack of interactivity and convenience. The score evaluation is lack of scientificalness and rationality. In addition, the teaching resources are not updated according to the users and the actual needs; the teaching platform is not timely maintained by specialized persons, the process of learning is not timely guided by professional teachers. Therefore, teaching resources construction and teaching methods reform are an urgent problem to be solved in applied undergraduate colleges.

In order to create a good self-learning conditions and improve students practical ability, we focus on teaching resources construction and teaching methods reform of data structure according to the characteristics of data structure and the requirements of practical personnel since 2005. The rich and suitable teaching resources, not only expand the way for students to obtain knowledge, but also broaden the students learning space. The teaching methods of students autonomous learning under the guidance of teachers, not only stimulate students learning enthusiasm, but also cultivate the students autonomous learning ability, improve the students practical ability.

\section{The Guiding Ideology of Teaching Resources Construction and Teaching Method Reform}

The teaching resources and the teaching methods must be suitable for the training of applied talents of computer specialty. The teaching resources must be practical, targeted, rich in content and effective in management. It includes textbook, multimedia courseware, examination, discussion, question answering, content retrieval and practice training etc. All kinds of teaching resources must be complement each other. The teaching method tack application ability training as the goal, tack student learning as the center, tack task driven as the approach, tack teacher guidance as the means. Forming the 
interactive mode of teaching and learning, realizing individuation learning, diversity of learning environment and guidance of learning process.

\section{Teaching Resources Construction}

Textbook Construction. Based on years of teaching experience and teaching results, We published "Data structure(C language version)" by Tsinghua University press In 2005 . With the development of computing technology, we published the second edition and third edition in 2012 and 2015 respectively. In the content organization, We tack the problem solving as the background, tack the logical structure of data, the physical structure of data and algorithm implementation as the main line, and tack the improvement of practical ability of students as the center. The structure, content description, examples and exercises are careful scrutinized according to the actual needs and the accept ability of students. The characteristics of the textbook are reasonable in structure, compact in content, coherent in knowledge, strong in logic and good in practice. All algorithms are given in the form of source code, the detailed notes and performance analysis of algorithm are given at the same time, the typical examples and a lot of exercises are used to enhance understanding of the algorithm. It can not only make the students master the knowledge quickly, but also cultivate the students ability of designing and analyzing algorithms.

In order to facilitate students autonomous learning, we published the "data structure learning and experimental guidance(C language version)" by Tsinghua University Press In 2005, we published second edition and third edition respectively in 2012 and 2015. It outlines the contents of each chapter of the textbook, points out the key points and difficult points, analyzes the typical case, gives answers of the exercises, sets up examination questions of independent evaluation, gives the thinking titles and practical subjects of independent learning. Where practice training topics, which designed by the teachers according to the teaching content and teaching experience, are closely related to practical problems, the answers can not be found in the textbook and internet. The difficulty of topics is in line with the students ability. Students are able to complete the practice training topics through independent inquiry, cooperative learning and teacher guidance. The characteristics of "data structure learning and experimental guidance" are strict structure, simple language, easy self-study. It not only helps students to digest the teaching content, but also improves the students programming ability, program debugging capability, analytical and solving problems capability.

Multimedia Courseware Construction. We developed the multimedia courseware of data structure in 2005, and updated in time with the development of computer technique and textbook edition. The courseware developed by PowerPoint. The courseware content is not a copy of the textbook, but it is demonstration of the algorithm with examples. The demo process can be controlled by hand and can be executed automatically and continuously. The courseware has good interactivity and guidance. In order to facilitate students autonomous learning, every algorithm is stored as a single file. With the help of dynamic demonstration, it is not only helpful for teachers to explain vividly, but also help students to understand thoroughly, it not only enriches the way for students to obtain knowledge, but also expands the means for teachers to impart knowledge, it not only inherited the advantages of traditional teaching, but also played the advantages of audio-visual teaching. It realizes the organic combination of blackboard teaching and multimedia courseware demonstration.

Network Resources Construction. The network teaching resources mainly include teaching program, experiment program, learning guidance, knowledge points system, multimedia courseware, algorithm source code, case base, examination question bank, practice training topics, examination system, answering system, online discussion etc.

The teaching program and the experiment program mainly include course introduction, instructional objectives, curriculum design, textbook, reference material, score evaluation method, prerequisite course and teaching calendar etc. The learning guidance includes instructional objectives, indicative abstract, key points and difficult points, learning reference and application background etc. The knowledge points system is the abstraction of all the knowledge points of the course, Includes knowledge points, corresponding chapter and pagination of textbook, instructional objectives etc. Students can choose their own learning content according to their own needs. The multimedia 
courseware mainly includes PPT, teaching video, reference materials, topics of thinking and discussion etc. The courseware links knowledge points and teaching objectives. The examination question bank contains more than 800 examination questions, includes single choice, judgment, application, algorithm analysis and algorithm design five types. The number of examination questions is large, representative is strong, coverage is wide, and the difficulty of examination questions is consistent with the ability of the students. The case base contains 50 typical cases. Each case is derived from practical application, and links knowledge points and teaching objectives. The practical training topics are designed according to the teaching progress, students ability and practical application, and updated every year. The examination system is developed for students to independent evaluation. After testing, the system will give the reference answer, the knowledge points, teaching objectives and prompt information. Online discussions are realized by answering system, QQ and WeChat etc, they meet the needs of interactive learning, collaborative learning and timely feedback.

The design of teaching resources accords with the cognitive rules of students, and embodies the main position of students. The teaching resource meets the basic requirements of applied talents training, and provides the guarantee for the reform of teaching methods.

\section{The Teaching Method of Students Autonomous Learning Guided by Teachers}

In the process of teaching, the teaching method of students autonomous learning guided by teachers is used.

Teachers transform their role from single knowledge teaching into all-round learning guidance. Teachers guide students learning independently in the classroom, in practice training and in application research, develop the guidance teaching process, compile guidance teaching plan. training students problem consciousness, cultivating students ability to find, analyze and solve problems.

The teaching process is changed from the traditional indoctrination teaching to the multi-form interactive communication. Teachers explain concisely the thinking, method, organization of knowledge and application of knowledge, guide gradually students by heuristic questions as well as the focus of analysis, answering questions after class to solve the problems encountered in learning and teaching process.

The training content is changed from simple verification to problem solving. Practical training topics are designed according to the teaching content and practical application. The whole training process is guided by professional teachers.

\section{Summary}

Based on students autonomous learning and students practical ability cultivating. We constructed the teaching resource of data structure course It has formed that the teaching mode of students autonomous learning, research learning, cooperative learning guided by teachers. The teaching resources of applicable and abundant provide new space-time for students to learn. The teaching methods focus on guidance and interaction, the initiative of students' autonomous learning has been fully aroused, the ability of students to discover, analyze and solve problems have been improved. In the past five years, there are more than $70 \%$ of students take the initiative to declare national and provincial innovation and entrepreneurship projects. The number of national and provincial innovation and entrepreneurship projects increase more than $12 \%$ per year. The number of national and provincial awards increase more than $9 \%$ per year, and the level of awards also increased year by year. The employment rate is more than $95 \%$ per year, and the level of employment increased year by year. The graduates have won wide acclaim from the employers.

"Data structure (C language version)" and "data structure learning and experimental guidance (C language version)" have been included into Liaoning Province general higher education programming textbook in 2014. "The research and practice on the construction of three-dimensional teaching material of data structure c" was awarded the first prize of Liaoning higher education undergraduate teaching achievement in 2012, "data structure (C language version)" and "data structure learning and 
experimental instruction ( $\mathrm{C}$ language version)" have been more than 50 universities selected as teaching materials. The network resources and teaching method have been adopted more than 20 universities and colleges.

\section{Acknowledgement}

This research was financially supported by the Education Committee of Liaoning province, China (No. L20160484), and Bohai Universities, China (No. BDJG-15-YB-A-003).

\section{References}

[1] J. van der Geer, J.A.J. Hanraads, R.A. Lupton, The art of writing a scientific article, J. Sci. Commun. 163 (2000) 51-59.

[1] Y.P. Qin, J. Liu, Z.G. Shen, Research and practice of construction of data structure, Journal of Bohai University(Natural Science Edition), 4(2009):362-365.

[2] Y.P. Qin, Research and practice on teaching method of data structure. Journal of Bohai University (Natural Science Edition), 4(2012):350-352.

[3] G.H. Geng, The reform of "data structure" and the construction of teaching resources, Computer Education, 11(2008):25-27.

[4] B.J. She, J. Sun, S.Y. Ji, Research on the construction of teaching resources database in application oriented undergraduate colleges. Modern Educational Technology, 4(2012):45-49.

[5] H.X. Zhang, Analysis on the construction of "data structure" resource sharing course, Modern Computer, 8(2014):51-54.

[6] H.J Yuan, Case design and application in the course teaching, Computer Education, 16(2013):90-94.

[7] F.Q.Cheng, Y.H Zhu, Q. Liu, On the construction of multi dimensional network teaching resources in colleges and universities, Computer Education, 2(20132):40-42.

[8] W.Z. Dai, Y. Yang, W.J Jiang, The programming database construction of data structure, Computer Education, 6(2016):70-71.

[9] L.P. Sun, J. Cheng, Y.L Luo, Research on the application of flipped classroom in data structure teaching, Computer Education, 24(2015):71-77.

[10]L.L. Huo, Z. Wang, J. Sun. Research on teaching method of data structure, Computer Education, 2(2015):73-76.

[11]M. Zhong, Teaching reform of data structure with the aim of cultivating applied talents, Computer Education, 14(2014):26-29.

[12] L F Wang, X Z Li, W. Li, ZPD-based multi-level teaching pattern in software engineering-A case study of data structure and algorithm course[J]. Second International Conference on Education Technology and Training, 2(2009):7-9. 